\title{
Práticas de letramento na família Possibilidades para a ação docente
}

\author{
Marcos Anderson Tedesco* \\ Marly Krüger de Pesce** \\ Rosana Mara Koerner**
}

\begin{abstract}
RESUMO: Reconhecer práticas de letramento no ambiente familiar de estudantes como possibilidade para a ação docente é a temática deste estudo. De cunho qualitativo, foram analisados dados gerados por meio de questionário e entrevistas com pais e professores de estudantes de duas turmas do ensino fundamental de escola de periferia de uma cidade Santa Catarina. Os resultados indicam que há práticas de letramento no ambiente familiar. Os pais têm a escola como principal agência de letramento e a visão de que a leitura e a escrita poderão dar um futuro diferente para os seus filhos.
\end{abstract}

Palavras-chave: Práticas de letramento. Família. Escola. Ação docente.

\section{Literacy practices in the family \\ Possibilities for teacher action}

\begin{abstract}
The theme of this study is the recognition of literacy practices in students' family environments as a possibility for teaching activity. From a qualitative perspective, data generated by means of a questionnaire and interviews with parents and teachers of students from two elementary classes from a school on the periphery of a city in the state of Santa Catarina were analyzed. The results indi-
\end{abstract}

* Formado em História, tem Mestrado em Educação pela Universidade da Região de Joinville. Atualmente é professor na Faculdade Refidim, em Joinville. Joinville/SC - Brasil. E-mail:<tedesco2005@gmail.com>.

** É formada em Letras, com doutorado pela Pontifícia Universidade Católica de São Paulo - PUC-SP. É professora no Curso de Letras e colaboradora no Mestrado em Educação da Universidade da Região de Joinville. Joinville/SC - Brasil. E-mail: <marlykrugerdepesce@gmail.com>.

*** Doutora em Linguística Aplicada pela UNICAMP, atua como docente nos cursos de Letras e de Pedagogia e no Mestrado em Educação da Universidade da Região de Joinville. Joinville/SC - Brasil. E-mail: <rosanamarakoerner@hotmail.com>. 
cate that there are literacy practices in the family environment. Parents identify the school as the main literacy agency and hold the view that reading and writing can give their children a different future.

Keywords: Literacy practices. Family. School. Teaching action.

\section{Prácticas de lectoescritura en la familia}

Posibilidades para la acción docente

RESUMEN: Reconocer prácticas de lectoescritura en el entorno familiar de estudiantes como posibilidad para la acción docente es el tema de este estudio. Con metodología cualitativa, se analizaron datos obtenidos por medio de cuestionarios y entrevistas con padres y profesores de alumnos de dos grupos de la enseñanza fundamental de una escuela situada en la periferia de una ciudad del estado de Santa Catarina. Los resultados indican que hay prácticas de lectoescritura en el entorno familiar. Los padres consideran que la escuela es la principal agencia de lectoescritura y tienen la visión de que la lectura y la escritura podrán proporcionar un futuro diferente a sus hijos.

Palabras clave: Prácticas de lectoescritura. Familia. Escuela. Acción docente.

\section{Pratiques d'alphabétisation en famille}

Possibilités pour l'enseignement

RÉSUMÉ: Le théme de cette étude est la reconnaissance des pratiques d'alphabétisation dans le milieu familial des éléves comme potentiel pour l'enseignement. Des données générales receuillies à travers un questionnaire et des entrevues avec des parents et des professeurs d'éléves de deux classes d'enseignement primaire d'une école de périphérie d'une ville de Santa Catarina ont été analysées sous une approche qualitative. Les résultats indiquent qu'il existe des pratiques d'alphabétisation dans l'environnement familial. Les parents voient l'école comme le principal agent d'alphabétisation et la lecture et l'écriture comme pouvant offrir à leurs enfants un avenir différent.

Mots-clés: Pratiques d’alphabétisation. Famille. école. enseignement. 


\section{Introdução}

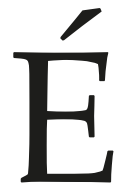

no âmbito das discussões que envolvem o letramento que se insere o texto, que pretende contribuir para a compreensão de como a ação docente poderá ser ressignificada a partir do reconhecimento das práticas de letramento no ambiente familiar do estudante. Para tal, serão apresentados resultados de aplicação de questionários e de entrevistas com pais de estudantes de duas turmas ( $5^{\circ}$ e do $9^{\circ}$ anos do ensino fundamental) de uma escola pública localizada na periferia de uma cidade ao norte de Santa Catarina. E também os depoimentos colhidos junto às duas professoras de Língua Portuguesa dessas turmas, nos quais foram buscados indícios acerca de como percebem a participação da família no processo de letramento dos estudantes. Assim, o artigo busca responder às indagações sobre quais são as práticas que ocorrem no espaço doméstico de estudantes de $5^{\circ}$ e $9^{\circ}$ ano e como são percebidas pelos seus professores.

\section{Algumas reflexões iniciais}

Como sujeitos inseridos em uma sociedade que tem na escrita a centralidade de muitas de suas atividades, somos impelidos à apropriação de uma série de competências e habilidades que vão além do simples aprendizado da tecnologia da escrita e da leitura. Estar alfabetizado não caracteriza estar preparado para os desafios de nossa sociedade,é apenas condição mínima para a inserção do sujeito nas complexas atividades do cotidiano.

Para Soares (2003, p.38), “[...] aprender a ler e a escrever e, além disso, fazer uso da leitura e da escrita transformam o indivíduo, levam o indivíduo a outro estado ou condição sob vários aspectos: social, cultural, cognitivo, linguístico, entre outros." A autora destaca a distinção entre a alfabetização e o letramento, afirmando que nem sempre um alfabetizado é um letrado. Porém, é importante lembrar que alfabetização e letramento são processos interdependentes e indissociáveis, embora distintos. Enquanto o alfabetizado é aquele que lêe escreve, o letrado usa socialmente, pratica e consegue relacionar-se socialmente através da leitura e da escrita. O sujeito é, pois, impelido a envolver-se em situações de uso da escrita (eventos) e, para tal, é preciso ter tido experiências que tornam possível esse envolvimento.

Chega-se, assim, aos conceitos de eventos e práticas de letramento. Para Pelandré e Aguiar (2009), os eventos de letramento são acontecimentos sociais que têm como base a compreensão ou produção de um texto, individualmente ou coletivamente. As práticas de letramento têm uma amplitude maior do que o evento, pois possibilitam que esse tenha atribuição de sentido por estar relacionado a essas práticas e por elas sendo mediado. Sendo assim, sem as práticas de letramento, os eventos não possuem 
significado. Essas práticas de letramento são, para Pelandré e Aguiar (2009, p.05), determinadas por "características sócio-históricas e, portanto, diferenciadas dependendo do período e do local em que se realizam e dos objetivos ao analisá-las."

Assim, a escola, compreendida como uma importante agência de letramento,-recebe estudantes durante um grande período de suas vidas e é, muitas vezes, um dos poucos lugares onde se encontram envolvidos em práticas de letramento para além daquelas de seu cotidiano, em boa parte dos casos (BALTAR, 2011). Porém, não é a única agência de letramento. Segundo Galvão (2004), o estudante vivencia eventos de letramento no ambiente familiar, na igreja, na associação, enfim, em diversos outros espaços além da escola. Para Cerutti-Rizzatti (2011, p.17), esses eventos "são entendidos como qualquer ocasião em que um texto escrito faça parte da natureza das interações dos participantes e de seus processos interpretativos".

Galvão (2004, p.141) afirma que o papel da família na vivência dos eventos e práticas de letramento é "tão forte que, em alguns casos, sobrepõe-se à escolaridade ou à profissão dos filhos". Mesmo em ambientes familiares onde os pais não leem e escrevem, é possível, muitas vezes, perceber a existência de eventos de letramento que, amparados pelas práticas de letramento, interagem com as atividades desenvolvidas na escolarização.

Para que aconteça essa interação, contudo, é necessário que o professor reconheça as práticas de letramento que fazem parte das referências e do contexto social dos estudantes. Para Cerutti-Rizzatti (2011), os alunos chegam à escola com realidades distintas sobre a leitura, vivenciam processos culturais específicos e isso tudo interferirá nas experiências no ambiente escolar. A autora destaca que:

Uma das possíveis respostas que se nos tem afigurado é o fato de que os eventos de letramento que têm lugar em muitas de nossas aulas de Língua Portuguesa não encontram sustentação nas práticas de letramento do entorno sociocultural e econômico em que vivem muitos de nossos estudantes... (Op.cit., p. 18)

Talvez em decorrência da maior valorização do que constitui a educação formal em detrimento da não-formal e/ou informal. Para Gohn (2006, p.22):

\footnotetext{
...a educação formal é aquela desenvolvida nas escolas, com conteúdos previamente demarcados; a informal como aquela que os indivíduos aprendem durante seu processo de socialização - na família, bairro, clube, amigos etc., carregada de valores e culturas próprias, de pertencimento e sentimentos herdados: e a educação não-formal é aquela que se aprende "no mundo da vida", via os processos de compartilhamento de experiências, principalmente em espaços e ações coletivas cotidianas.
}

Na educação informal não há um lugar rígido, horário ou um currículo definido. Há sim um espaço primeiro, o ambiente familiar, e é aí que, através de variadas interações, a criança vai aprendendo e desenvolvendo hábitos que são próprios do seu grupo social, que os conhecimentos são partilhados a partir de interações socioculturais não 
programadas. Para Gaspar (2002), nessa modalidade o ensino e a aprendizagem ocorrem de forma espontânea, sendo que, muitas vezes, os envolvidos no processo não têm consciência de que estão nele inseridos.

A escola, segundo Pillotto e Tamanini (2012), "trabalha essencialmente com memórias, saberes, identidades, patrimônios herdados, acúmulos sociais representados fortemente pelos conhecimentos repassados em seus conteúdos programáticos". Sua função social é extremamente significativa e ela não pode abrir mão da valiosa bagagem cultural que a criança traz de casa, incluindo-se aí suas experiências com a escrita.

Essa escolarização, segundo Freire (2007), está desvinculada da realidade e acaba por impor meios de aprendizagem superficiais e passivos, ocasionando falta de criticidade frente à sociedade. Assim, por vezes, aquilo que a criança traz como referência do seu ambiente familiar acaba por não fazer parte do sistema formal de ensino, sendo então desvalorizado em função de um formato que impõe uma "cultura" artificial e com pouco significado frente ao que é cotidiano do indivíduo.

Para Nogueira e Nogueira (2002, p. 32), "formalmente, a escola trataria a todos de modo igual, todos assistiriam às mesmas aulas, seriam submetidos às mesmas formas de avaliação, obedeceriam às mesmas regras e, portanto, supostamente, teriam as mesmas chances." Mas Bourdieu e Passeron (2011) mostram que isso não acontece e as chances são desiguais. O que explica essa desigualdade é o "capital cultural", que, para os autores é o elemento herdado do meio familiar com maior impacto na definição da trajetória escolar. A posse dele favorece o desempenho escolar já que facilita a aprendizagem dos conteúdos escolares, legitimados pela sociedade dominante.

Quando a escola, ao propor o uso social da escrita, valoriza as práticas de letramento com base em um "capital cultural" já existente, consegue atribuir sentido ao que é ensinado e aprendido. Não apenas a escola vive esse processo, mas também a família e a comunidade, sendo espaços de constituição e ressignificação de valores culturais num movimento contínuo e sempre inconcluso. Para Freire (1996), o indivíduo precisa se relacionar com o mundo que o cerca, não apenas constatando o que ocorre, mas também intervindo como sujeito a todo o tempo.

Nóvoa (2002) defende que a escola, para fazer sentido para os estudantes e suas famílias, precisa rever seu papel. A escola e o professor precisam abraçar uma concepção de espaço aberto que acolha a sociedade e suas instituições, tanto culturais quanto científicas, e que possa ver na comunidade a concretização de uma participação marcante, permanente e reflexiva. Quando a escola promove um movimento dialético entre as histórias de vida trazidas do ambiente familiar e o vivido no seu espaço, o estudante terá mais chances de se perceber como alguém que se constitui enquanto sujeito e não mais como alguém que passivamente aceita o que lhe é imposto.

Assim, reconhecer as experiências com a escrita vivenciadas por seus estudantes no ambiente familiar poderá se configurar em uma interessante postura a ser assumida 
pelo professor, especialmente no planejamento das ações pedagógicas voltadas à promoção do letramento da turma.

\section{O percurso metodológico}

Considerando-se o objetivo proposto, este estudo optou por uma abordagem de caráter qualitativo, que tornasse possível a compreensão de processos vividos por determinados grupos sociais. A pesquisa qualitativa, ao ser empregada em um estudo que visa compreender as relações sociais, é bastante útil, já que permite visualizar as pluralidades humanas em seus detalhes, desde que seja coerentemente aplicada. Para Flick (2004, p.20),

[...] os aspectos essenciais da pesquisa qualitativa [...] consistem na escolha correta de métodos e teorias oportunos, no reconhecimento e na análise de diferentes perspectivas, nas reflexões dos pesquisadores a respeito de sua pesquisa como parte do processo de produção de conhecimento, e na variedade de abordagens e métodos.

Trata-se de uma pesquisa feita com uma turma do $5^{\circ}$ ano e outra do $9^{\circ}$ Ano $^{1}$, envolvendo os pais dos estudantes e seus professores de Língua Portuguesa ${ }^{2}$. Foi em uma escola da rede municipal (pública), localizada na periferia de uma cidade ao norte de Santa Catarina. Como instrumentos de geração de dados usaram-se questionários de sondagem (com questões abertas e fechadas) e entrevistas semiestruturadas. Para o presente artigo serão trazidos os resultados que possibilitam o reconhecimento das práticas de letramento no ambiente familiar dos estudantes ${ }^{3}$.

As respostas dos professores foram confrontadas com as respostas dos pais dos estudantes obtidas também por meio de um questionário de sondagem (enviado a todos os pais) e por meio de entrevista semiestruturada, com uma amostra constituída por representantes de quatro famílias (sorteadas entre as que se disponibilizaram para entrevista a partir de questionário). A intenção foi buscar contradições, desvios, conformações e o quanto isso pode afetar o fazer pedagógico desses professores. É importante ressaltar que a participação das professoras ${ }^{4}$ e famílias foi voluntária a partir de comunicação, através de carta a todos os envolvidos antecipadamente a cada etapa. Os sujeitos estão identificados pelas seguintes siglas: P1 e P2 para as professoras, e F1, F2, F3 e F4, no caso dos responsáveis pelas famílias.

Os questionários ${ }^{5}$ (tanto para os professores como para os pais/responsáveis) tinham o objetivo de fazer uma primeira aproximação dos sujeitos da pesquisa. Uma vez selecionados os professores e os familiares, foram agendados encontros para a realização da entrevista (audiogravada), que visava à complementação das informações 
do questionário. Alguns excertos desse material serão trazidos para o interior do texto e transcritos tal qual emitidos pelos sujeitos.

No bairro onde se localiza a escola pesquisada, a média de moradores por domicílio, a taxa de dependentes entre a população residente, o percentual de crianças e adolescentes fora da escola, a taxa de defasagem no ensino fundamental e o percentual de responsáveis por domicílio com baixa instrução estão entre as maiores da cidade.

As duas professoras possuem significativa experiência, tanto que na entrevista fazem menção à possibilidade de aposentadoria. Atuam em mais de um local de trabalho e têm carga horária menor que $40 \mathrm{~h} / \mathrm{a}$, o que faz com que busquem outros locais. Agem nessa escola há menos de cinco anos.

Foi entregue aos familiares dos alunos um total de 55 questionários, dos quais 31 foram devolvidos, sendo $55 \%$ do $5^{\circ}$ Ano e $45 \%$ do $9^{\circ}$ Ano. Vale relatar que no momento da entrega dos questionários, as professoras se mostraram um tanto céticas quanto à devolução, que ocorreria por parte dos pais, talvez, baseando-se na percepção de que parte dos familiares tem baixa escolaridade e, portanto, não se envolveria com uma prática de escrita: "Nós temos aqui pais analfabetos" (P2). No entanto, 55\% de devolução não é um índice a ser desprezado, o que indica que os pais se envolveram no preenchimento do questionário, que poderia ser caracterizado aqui como um evento de letramento. As mães correspondem a dois terços dos que responderam ao questionário. Com relação à escolaridade, apenas um pai está frequentando um curso universitário na área de Engenharia Química, $15 \%$ possui curso técnico completo, $18 \%$ o ensino médio completo, $18 \%$ o ensino médio incompleto, $11 \%$ o ensino fundamental completo, $29 \%$ o ensino fundamental incompleto e 3,7\% são analfabetos.

Na próxima seção serão discutidos os resultados obtidos por meio do questionário ou por meio das entrevistas.

\section{Práticas de letramento no ambiente familiar}

Com a intenção de identificar as práticas de letramento no ambiente familiar dos alunos foi perguntado aos pais, através do questionário, sobre as atividades mais frequentes no dia-a-dia em família. As mais citadas foram os afazeres domésticos, as práticas religiosas, a leitura e os passeios em família. Em um total de 12 atividades distintas apontadas pelos pais, a leitura de livros foi a quarta mais citada, um dado altamente significativo, pois nessa comunidade há uma série de dificuldades ao acesso a esse tipo de material. Segundo Soares (2003, p.58), em muitas localidades acontece a alfabetização, mas não são dadas as condições para a leitura e a escrita: "Não há material impresso posto à disposição, não há livrarias, o preço dos livros e até dos jornais e revistas é inacessível, há um número muito pequeno de bibliotecas. Como é possível tornar-se letrado em tais 
condições?" Os pais dessa localidade, segundo os dados levantados na pesquisa, têm buscado meios de driblar essa real dificuldade, já que a quantidade dos que praticam a leitura de livros com frequência indicou um índice destacado.

Com relação ao uso de computador com acesso à internet, 65\% das famílias não dispõem do aparelho em casa e apenas $6 \%$ têm acesso a revistas e jornais. Na região, a telefonia atende poucas ruas, inexistem livrarias e bancas de revistas e jornais e muitas famílias moram em terrenos irregulares onde até a energia elétrica é obtida de forma irregular. Aqueles que têm acesso a materiais que despertem o interesse pela leitura e a escrita é porque os buscam em outras instâncias, como, por exemplo, uma biblioteca no local de trabalho, uma mesa repleta de revistas de um consultório odontológico ou, ainda, em uma porta da igreja, preparando-se para a liturgia.

Com relação à leitura, 68\% dos pais disseram gostar de ler. Entre os materiais contemplados nessas leituras, foram citados os seguintes: Bíblia, jornais, gibis, revistas, livros de autoajuda, religiosos, romances, educativos, técnicos, de empreendedorismo e de história. Os materiais apontados indicam, em sua maioria, livros que, de alguma forma, trazem alguma contribuição para a vida em seu cotidiano, com todos os seus desafios. Lê-se, talvez, para mudar de condição. Isso gera certa crença no poder de transformação do livro:

Olha, quando tenho tempo, sim. É difícil ter tempo para ler mais. Elas [as filhas] leem mais e o meu marido lê mais. Nós lemos à noite antes de ir dormir. Cada um lê um livro. Ela lê o dela, o meu marido está lendo um sobre "Negras Raízes" e eu estou lendo um de dieta: "100 maneiras para emagrecer", mas estou lendo [risos]. Ele é negro e tem curiosidade de saber assim como é a história, ele lê muito. Elas também leem bastante. Qual o nome do livro que você leu? Aquele último. "De meninas para meninas". Histórias de meninas. (F1)

Nessa fala há várias questões que merecem ser destacadas: quando a mãe faz referência ao momento em que a leitura acontece, à noite antes de ir dormir, faz uma indicação de esforço, mas, ao mesmo tempo, da instalação de um hábito, normalmente referenciado quando se fala de leitura. Já ao usar a expressão mas estou lendo, esse mas indica que há uma avaliação depreciativa desse tipo de material de leitura. Apesar disso, o que está sendo valorizado aqui é o ato de ler em si, e isso é frisado pelo uso do gerúndio lendo que dá a ideia de algo contínuo, frequente. Quando a mãe usa a palavra muito, ao referir-se ao quanto o seu esposo lê, indica um dos motivos que o movem para a leitura. Na verdade, não muito diferente dela, que está lendo um livro não pelo simples ato de ler, mas porque busca algo que possa ajudá-la. Finalmente, ao informar o livro que a filha lia, a mãe reconhece que há leituras para diferentes finalidades.

Um exemplo da superação em busca do acesso a materiais escritos pode ser encontrado na fala de F4: 
Panfleto, jornal, revista, livro, Bíblia, revista de cozinha [...] livro de histórias, romântico. Gosto de tudo. Pego na biblioteca, compro, pego emprestado com a minha vizinha. A gente compartilha bastante, a minha vizinha eu conheço desde criança.

A prática da escrita mais recorrente é aquela que acontece com a intenção de acompanhar os estudos desenvolvidos pelos filhos: Escrevo só para ajudar ele na tarefa para não ter erro de português. Tirando a Bíblia, ler e escrever, só para ajudar ele na escola. Escrevo pouco. Escrevo para não esquecer o que tenho que fazer. (F2)

Ao serem questionados se os filhos tinham o hábito da leitura, $42 \%$ dos 31 pais responderam que sim, $36 \%$ responderam que às vezes e $22 \%$ responderam que não. As leituras se concentram mais em torno de gibis, literatura infanto-juvenil e livros religiosos. Os pais reconhecem a importância do ato de ler na vida dos filhos: Eu me sinto muito feliz de elas lerem, pais sempre gostam, né. Ainda mais quando aprendem. (F1) O aprender deixa a leitura mais produtiva. $O$ não dito é o de que a leitura pela leitura (leitura de fruição) tem um valor menor do que aquela que leva à produção de conhecimento. Para Fairclough (2001, p. 40), "o que é 'dito' em um texto é 'dito' em relação a um lastro cultural do 'não-dito", que na fala desse pai está impregnada pela ideologia capitalista do fazer produtivo.

Há práticas de leitura coletiva: No final de semana a gente para e lê junto a Bíblia. A esposa lê, e a gente senta junto, nós sete, e ouve o que ela lê. Aí a gente conversa o que entendeu. É muito importante. (F3) Em uma família onde o pai lê com muita dificuldade e mora em um lugar onde não há rede de energia elétrica regular (constantemente há quedas que ocasionam "apagões"), no meio de uma invasão de terras, ainda é encontrado um momento em que nove pessoas se sentam ao redor de um livro, leem e debatem acerca dele.

Sobre leitura por eles na presença dos filhos, $58 \%$ responderam que sim. É importante destacar que a leitura é mais recorrente no caso da presença de filhos menores, do 50 ano. Talvez ainda esteja um pouco presente a ideia de que é preciso ler para as crianças. As condições de trabalho podem contribuir para tal cenário. Pais que trabalham longe de casa demandam de mais tempo de deslocamento, o que diminui, consequentemente, o tempo de permanência no ambiente familiar, sem mencionar a questão do cansaço. Quando perguntados se costumavam ler histórias infantis para os filhos, 19\% disseram que sim, $46 \%$ afirmaram que liam às vezes e $35 \%$ não liam. O livro infantil tem um custo geralmente elevado, o que pode ter contribuído para os baixos números, além da recorrente falta de tempo.

$\mathrm{Na}$ fala de F1 observam-se algumas das formas de incentivo à leitura:

Como ele [o marido] trabalha na [nome de uma indústria de grande porte da área de metal-mecânica], e eles têm a biblioteca lá, sempre traz livro, traz filme. Pergunta o que ela [a filha] quer ler, que filme quer ver. E traz. Se ela tem vontade de ler um livro diferente, a gente procura e eu compro para ela. Nesse lado, mesmo a gente tendo poucas condições, se tem vontade, eu dou um jeito e compro para ela. 
Aqui parece haver o reconhecimento de que o filme pode também ser uma prática cultural mais elaborada, tanto é que compõe a resposta ao lado da palavra livro. Trata-se de uma visão mais abrangente dos bens que possibilitam acesso a uma cultura diferenciada. Além disso, esse discurso nos reporta ao que Bourdieu e Passeron (1964) dizem ao afirmarem que há o reconhecimento da necessidade de acesso a um capital cultural aparentemente distanciado. E para tal, não são medidos esforços. De certa forma, reforça um pouco a ideia do mito do letramento (Graff, 1994), o conceito que confere à escrita um poder que ela não tem. A escrita é vista como algo a ser alcançado, e, com ela, uma série de vantagens: Bom trabalho, bom serviço. Ganhar mais do que eu ganho. Assim, eu sei que um dia eles vão poder dar mais para os filhos deles do que eu dou para eles. (F4)

Para os pais, ler é sinônimo de educação. E educação é vista na perspectiva do comportamento, algo bastante caro no caso da escola pesquisada, inserida em um bairro com histórico de violência. Também há a ideia de leitura e escrita como algo da escola: Às vezes até o que não é atividade da escola eles querem escrever, carta pros tio, pras tia. Eu só digo que o caderno deles é independente e eles têm que cuidar porque se não vira uma borraceira. Não pode arrancar a folha (F3). Com base nessa afirmação duas questões podem ser apontadas: primeiro, o uso da palavra até que indica a surpresa do familiar, julgando que escrever algo não recomendado pela escola é algo digno de ser citado. Segundo, a ênfase no capricho, indicando uma visão de escrita antiga, que associa o ato de escrever ao ato de desenhar as letras. É uma visão bastante presente em pessoas com pouca escolaridade, já que é algo enfatizado nas séries iniciais, durante o processo de alfabetização, mas abandonado quando a criança já se encontra plenamente alfabetizada e realizando muita produção escrita.

De acordo com Pelandré e Aguiar (2009, p.49), as práticas de letramento são determinadas por "características sócio-históricas" e, assim, se diferenciam, dependendo do período e do local onde acontecem. Com base nessa premissa, entende-se que os professores, e entre eles o de Língua Portuguesa, levem em consideração na sua prática o contexto onde o aluno se insere, sua família e comunidade. Uma das professoras assim descreve o bairro:

A comunidade é muito carente. A maioria é bastante carente. Vida social não tem. Muita pobreza. Falta de envolvimento das famílias com as crianças. Muita separação, baixando o nível e mexendo muito com as crianças. Existe muito catador de lixo por aí. (P1)

A professora percebe a situação econômica e social precária da comunidade e como essa situação pode vir a prejudicar as relações familiares gerando impacto negativo nas crianças que frequentam a escola. A outra professora, durante a entrevista, relatou que ao ler os textos produzidos pelos seus alunos toma conhecimento de diversas situações que fazem parte do cotidiano, algo que a emociona muito: Eu me envolvo bastante quando 
eu leio o texto das crianças, eu chego a chorar. Eles me contam como são tratados, através dos textos eu já descobri crianças que foram vítimas de violência sexual. (P2)

Quando questionadas sobre se as características específicas do ambiente familiar influenciam nas aulas, as professoras declararam que acham muito importante conhecer a realidade familiar dos alunos. Porém, quando perguntado sobre a frequência que esse conhecer a realidade é levado em conta na hora de planejar as atividades aplicadas em sala, as duas professoras declararam que esse conhecimento não as auxilia muito na preparação das aulas, embora algumas informações ajudem a entender possíveis dificuldades em alguns alunos. É importante destacar que em respostas a outras perguntas, as professoras revelaram que em alguns momentos sua prática pedagógica é orientada pelo contexto familiar do aluno. P1 faz a seguinte consideração acerca dessa questão norteadora:

Interfere muito né, bastante. Se você tem um grupo de 33 alunos, em que digamos, 22 desses não têm um acompanhamento em casa, então aí você já percebe que os pais não estão interessados. Eles colocam as crianças na escola porque elas têm que vir. Mas na verdade eles não se envolvem. (...) Isso prejudica muito o aprendizado das crianças porque eles não têm o incentivo em casa. Bastante complicado essa região aqui.

Em uma fala de P2, percebe-se sua preocupação em trazer para a sala de aula uma abordagem significativa para o aluno: O tema lá da leitura é grafite e pichação, coisa que eles estão cansados de ver. Estão vendo comentário de que se grafite é arte ou se pichação é arte. (...) Algo que faz parte da realidade deles. Ao fazer uso do tema grafite e pichação, a professora está aplicando o que aprendeu sobre a o ensino por meio de gêneros, em cursos de capacitação dos quais participou. A ideia dessa abordagem é se apropriar do que os alunos já sabem, valorizando as práticas de letramento nas quais já tenham se envolvido.

Com relação ao fato de usar ou não o conhecimento acerca das referências culturais dos estudantes, incluindo as práticas de letramento vivenciadas no ambiente familiar dos alunos no desenvolvimento das atividades em classe, as professoras responderam negativamente. Ainda assim, há casos em que reconhecem a ocorrência de práticas envolvendo a leitura e a escrita feitas em casa, vendo-as de modo favorável: Penso que a maioria lê, pelo menos, um gênero textual. (P1) A professora do 9oA Ano respondeu que alguns liam. Indica uma visão favorável, reconhecendo os esforços dos pais (ainda que haja a leitura de, pelo menos, um gênero textual - Grifo nosso).

No questionário foi perguntado às professoras como consideravam as atividades de leitura e escrita no ambiente familiar de seus alunos:

Para uma aprendizagem de excelência, são de suma importância a influência e o envolvimento familiar na vida das crianças. Desde pequenos, possibilitar o convívio com o letramento através de jogos e imagens. (P1)

Criam o hábito de leitura no aluno oferecendo a ele mais recursos na produção textual, facilidade na interpretação e melhora no rendimento escolar. (P2) 
P1 faz um discurso bastante generalizante, já que não está se referindo diretamente à comunidade no entorno da escola onde atua. Quando faz referência à associação do letramento com jogos e imagens, parece indiciar certa incompreensão da dimensão do conceito. Por que ela não associou inicialmente com algum material escrito? No discurso de P2 subjaz a preocupação quase que exclusiva com o desempenho escolar. Não há nenhuma referência a alguma capacidade de melhor circulação do estudante em uma sociedade grafocêntrica, o que reduz sua fala a certo lugar-comum na fala dos professores, especialmente de Língua Portuguesa, sempre preocupados com questões de produção escrita e de interpretação, habilidades fundamentais para o bom desempenho escolar.

\section{Considerações finais}

Nesse texto foram trazidos dados sobre práticas de letramento no ambiente familiar e como os professores enxergam tais práticas. O exercício proposto foi o de reconhecimento de tais práticas, na crença de que se trata de uma estratégia que pode ressignificar o fazer pedagógico para as questões do letramento.

Através dos questionários e entrevistas semiestruturadas foi identificada a diversidade e a quantidade de práticas de letramento no ambiente familiar de estudantes de $5^{\mathbf{0}}$ e $9^{\circ}$ ano de um bairro de periferia, configurado pelas professoras como um local bastante complicado, no qual os pais não se envolvem. Contudo, tal percepção pouco se confirmou nos dados relacionados aos pais dos estudantes. Há atividades de leitura e de escrita, ainda que não sejam as almejadas pela escola. Os pais se mostraram preocupados com a leitura dos filhos, talvez movidos pela crença de que o domínio da habilidade poderá contribuir para a obtenção de um bom trabalho, bom serviço. Ainda que isso aponte para o poder meio mágico conferido pelos pais à escrita (mito do letramento), também mostra que há, sim, preocupação para com a educação dos filhos.

As condições socioeconômicas adversas podem ter interferido na aquisição de materiais de leitura, como no caso dos livros de histórias infantis; contudo, não impediram que houvesse gestos de leitura dos pais, visualizados pelos filhos. São cenas que vão configurando as práticas de letramento no espaço da casa, dando-lhes significado e imprimindo valores nos que nelas estão envolvidos. E tais significados e valores serão amalgamados com os significados e valores adquiridos no espaço escolar, com suas práticas de letramento mais organizadas e mais estruturadas. Não há como se inserir em novas práticas de leitura e de escrita, menosprezando tudo o que se sabe sobre tais habilidades.

Ao desprezar as experiências prévias com a leitura e a escrita, a escola propõe aquilo que Freire (2007) considerou como aprendizagem superficial e passiva, resultando na falta de criticidade frente ao que ocorre na sociedade. Ler e escrever na escola acabam 
por se transformar em práticas artificiais, porque desvinculadas de todo um contexto. As professoras, sujeitos da pesquisa, deram indícios claros de que reconhecem o contexto social no qual a escola se encontra inserida. Contudo, em suas falas transparece um pouco do senso comum, que rege o que se diz sobre as periferias de grandes cidades, a de que ali moram famílias desestruturadas, pouco atentas ao que acontece na escola. No confronto das falas de pais e professores, esse senso comum não se confirma.

Talvez seja mesmo necessário criar situações em que seja possível o contato mais próximo com as famílias dos alunos para melhor percepção das práticas de letramento e das referências familiares. O reconhecimento do que se faz em casa talvez possa contribuir para o planejamento de práticas pedagógicas mais significativas, menos artificiais, menos superficiais.

Recebido em 31/07/2015 e aprovado em 15/02/2016

\section{Notas}

1 São turmas que encerram os dois ciclos do ensino fundamental; daí o motivo da escolha.

2 Uma professora para cada turma, que cumpriam a função de regência, que se caracteriza pela responsabilização do que acontece em cada uma delas.

3 Embora a temática central fosse a questão das práticas de letramento, outros temas também foram abordados no questionário e na entrevista que não serão, contudo, aqui apresentados.

4 Trata-se de profissionais do sexo feminino, daí a opção por adotar o gênero feminino ao nos referirmos aos professores.

5 Acompanhados dos Termos de Consentimento Livre e Esclarecido.

\section{Referências}

BALTAR, Marcos. Letramentos e gêneros textuais midiático-escolares. Revista Letras, v. 20, n. 40: 177-190, 2010.

BOURDIEU, Pierre; PASSERON, Jean Claude. A reprodução. 4ae ed. Trad. Reynaldo Bairão. PetrópolisRJ: Vozes, 2011.

CERUTTI-RIZZATTI, Mary Elisabeth. Relações entre formação escolar do leitor, práticas de letramento e eventos de letramento. In: CAVASSIN, Regina Back; KOERNER, Rosana Mara; SILVA, Nívia Röling (Orgs). Caderno de resumos e programação do 1. ${ }^{\circ}$ Seminário de Práticas de Linguagem em Sala de Aula. Joinville (SC), Univille: 16-20, 2011.

FAIRCLOUGH, Norman. Discurso e mudança social. Brasília: Editora Universidade de Brasília, 2001. 
FLICK, Uwe. Uma introdução à pesquisa qualitativa. Porto Alegre: Bookman, 2004.

FREIRE, Paulo. Pedagogia da Autonomia: saberes necessários à prática educativa. 4 ed. São Paulo: Paz e Terra, 1996.

Educação como prática da liberdade. 30ªำ ed. Rio de Janeiro: Paz e Terra, 2007.

GALVÃO, Ana Maria Oliveira. Leitura: algo que se transmite entre as gerações? In RIBEIRO, Vera Masagão. (Org.). Letramento no Brasil: reflexões a partir do INAF. 2a Ed. São Paulo: Global, 2004.

GASPAR, Alberto. A educação formal e a educação informal em ciências. In.: MASSARANI, Luisa; MOREIRA, Ildeu de Castro; BRITO, Fatima. (Orgs.) Ciência e público: caminhos da divulgação científica no Brasil. Rio de Janeiro: Casa da Ciência, 2002.

GOHN, Maria da Glória. Educação não-formal, participação da sociedade civil e estruturas colegiadas nas escolas. Revista Ensaio: Avaliação e Políticas Públicas em Educação. Vol.14, n.50, 2006, p. 27-38.

GRAFF, Harvey J. Os labirintos da alfabetização: reflexões sobre o passado e o presente da alfabetização. Porto Alegre: Artes Médicas, 1994.

NOGUEIRA, Cláudio Marques Martins; NOGUEIRA, Maria Alice. A sociologia da educação de Pierre Bourdieu: Limites e contribuições. Revista Educação \& Sociedade, ano XXIII, n.78: 15-36. 2002.

NÓVOA, Antonio. Formação de professores e trabalho pedagógico. Lisboa, Portugal: EDUCA, 2002.

PELANDRÉ, Nilcéa Lemos; AGUIAR, Paula Alves de. Práticas de letramento na Educação de Jovens e Adultos. Revista Fórum Linguístico. V.6, N.2: 55-65, 2009.

PILLOTTO, Silvia Sell Duarte; TAMANINI, Elizabete. Educação popular e patrimônio cultural: a complexidade do modo de construir saberes formais e não formais interdisciplinares entre museu, escola e comunidade. In: CAMPOS, Rosânia; VENERA, Raquel Alvarenga Sena. (Orgs.) Abordagens teórico-metodológicas: primeiras aproximações. Joinville (SC): UNIVILLE, 2012.

SOARES, Magda. Letramento: um tema em três gêneros. Belo Horizonte: Autêntica, 2003. 